\title{
Diabetes and the Affordable Care Act
}

\author{
Mark R. Burge, MD, and David S. Schade, MD
}

\begin{abstract}
The Affordable Care Act- "Obamacare"-is the most important federal medical legislation to be enacted since Medicare. Although the goal of the Affordable Care Act is to improve healthcare coverage, access, and quality for all Americans, people with diabetes are especially poised to benefit from the comprehensive reforms included in the act. Signed into law in 2010, this massive legislation will slowly be enacted over the next 10 years. In the making for at least a decade, it will affect every person in the United States, either directly or indirectly. In this review, we discuss the major changes in healthcare that will take place in the next several years, including (1) who needs to purchase insurance on the Web-based exchange, (2) the cost to individuals and the rebates that they may expect, (3) the rules and regulations for purchasing insurance, (4) the characteristics of the different "metallic" insurance plans that are available, and (5) the states that have agreed to participate. With both tables and figures, we have tried to make the Affordable Care Act both understandable and appreciated. The goal of this comprehensive review is to highlight aspects of the Affordable Care Act that are of importance to practitioners who care for people with diabetes by discussing both the positive and the potentially negative aspects of the program as they relate to diabetes care.
\end{abstract}

\section{Introduction}

$\mathbf{T}$ "he Affordable Care Act (ACA), otherwise known as "Obamacare," was passed by Congress and signed into law by President Obama on March 23, 2010. It survived a U.S. Supreme Court challenge in 2012, which upheld the constitutionality of the ACA's individual mandate as an exercise of Congress's taxing power. Some parts of it became law in 2014, with other parts to be phased in by 2020. It will initiate the most substantial change in U.S. healthcare since the passage of Medicare in 1965. The ACA bill is a massive piece of legislation comprising 906 pages. It contains numerous changes to the existing U.S. healthcare system affecting, in one way or another, every U.S. citizen. One of the prime motivating reasons for this bill was to provide health insurance to the approximately 40 million Americans who are currently not covered by some type of health insurance. It was also designed to address specific deficiencies that now exist in the current healthcare system. The ACA has a long legacy of legal challenges and legislative manipulations resulting in many modifications as detailed in Figure 1.,2

As is characteristic of any new federal legislation, there are both proponents and opponents of ACA. For example, the Office of Management and Budget of The White House strongly supports the ACA. The Office has stated: "The Affordable Care Act is a once-in-a-generation change to the
U.S. health system. It guarantees access to health care for all Americans, creates new incentives to change clinical practice to foster better coordination and quality, gives physicians more information to make them better clinicians and patients more information to make them more valueconscious consumers, and changes the payment system to reward value.",3 In contrast, individuals who believe that they already have sufficient health insurance and feel that the ACA will increase their insurance premiums or that the legislation goes beyond the U.S. Government's taxing authority typically oppose the ACA. The purpose of this editorial is not to support or criticize the ACA, but to identify specific parts of it that may be of particular interest to individuals who care for patients with diabetes. This population has been chosen because procuring access to, and utilizing, healthcare is often a major challenge to their lifestyle and standard of living. ${ }^{4}$

Diabetes is also a major epidemic disease in the United States. Approximately 79 million U.S. citizens have either diabetes or prediabetes. Our list of chosen topics is not allinclusive. However, an attempt has been made to describe the major portions of the ACA that will be of value to healthcare workers in helping their patients make appropriate choices (Fig. 2). Less comprehensive summaries of the effect of the ACA on patients with diabetes have been published., If Medicare is any guideline, Congress may make future

University of New Mexico School of Medicine, Albuquerque, New Mexico. 


\begin{tabular}{|c|c|c|}
\hline $\begin{array}{c}1986 \\
\text { Emergency } \\
\text { Medical } \\
\text { Treatment and } \\
\text { Active Labor } \\
\text { Act }\end{array}$ & $\begin{array}{c}1989 \\
\text { Heritage } \\
\text { foundation } \\
\text { proposes an } \\
\text { individual } \\
\text { mandate }\end{array}$ & $\begin{array}{c}1993 \\
\text { President } \\
\text { Clinton } \\
\text { proposes a } \\
\text { healthcare } \\
\text { reform bill }\end{array}$ \\
\hline
\end{tabular}

\begin{tabular}{|c|c|c|}
\hline $\begin{array}{c}2009 \\
\text { Obama } \\
\text { announces to } \\
\text { Congress his } \\
\text { support for } \\
\text { healthcare } \\
\text { reform }\end{array}$ & $\begin{array}{c}2006 \\
\text { Massachusetts } \\
\text { enacts the } \\
\text { Insurance } \\
\text { Expansion Bill }\end{array}$ & $\begin{array}{c}1997 \\
\text { Congress } \\
\text { enacts State } \\
\text { Children's } \\
\text { Health } \\
\text { Insurance } \\
\text { Program }\end{array}$ \\
\hline
\end{tabular}

FIG. 1. An abbreviated legislative history of the Affordable Care Act (ACA). Many parts of previous regulations and bills (some of which became law, some did not) were incorporated into the final Affordable Care Act of 2010. Adapted from information from Wikipedia. ${ }^{1}$

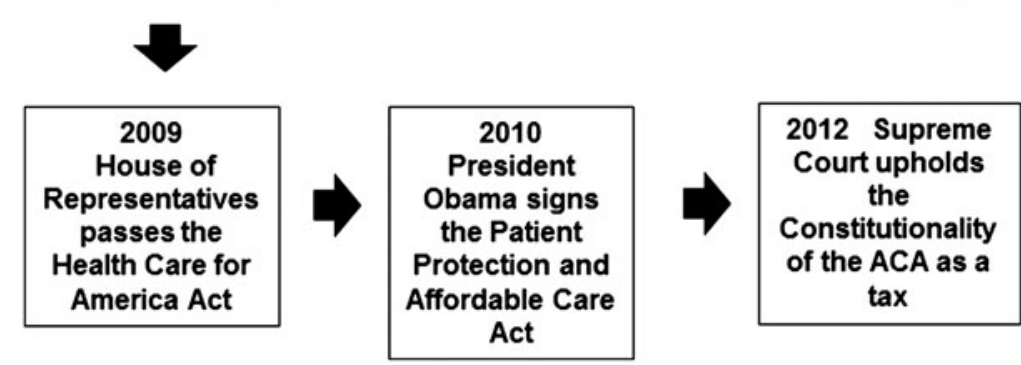

changes to the ACA, thereby rendering this current description of it in need of modification.

\section{Overview of the ACA}

To better understand the specific sections of the ACA that directly relate to persons with diabetes, a brief overview of its construction is instructive. There are two basic mechanisms within it that are designed to increase insurance coverage for eligible Americans (not everyone is eligible, as listed in Table 1). ${ }^{6}$ First, the eligibility for Medicaid benefits will be expanded to include individuals below $138 \%$ of the federal poverty level (Table 2). Second, state-based insurance plans will be established whereby individuals and small businesses can buy health insurance plans. In order to insure that all individuals will be able to afford these plans, individuals below $400 \%$ of the federal poverty level will be eligible for federal subsidies called "advanced premium tax credits." Because people 65 years of age and over are already covered by Medicare, the Office of Management and Budget estimates that the ACA will increase the proportion of insured nonelderly citizens to $94 \%$ of the population.

Not all individuals in the United States will be covered by ACA medical insurance. Individuals not covered include (1) illegal immigrants (although they still remain eligible for emergency medical services under provisions of the 1986 Emergency Medical Treatment and Active Labor Act), (2) U.S. citizens who are eligible for Medicaid but who are not enrolled in this program, and (3) U.S. citizens not otherwise covered but who choose to pay the annual penalty instead of purchasing insurance. It is anticipated that this group will be mostly younger and single Americans. (4) U.S. citizens whose insurance premiums would cost more than $8 \%$ of their household income are exempt from paying the annual penalty. And finally, (5) citizens who live in states that opt out of the
Medicaid expansion and who qualify for neither Medicaid coverage nor are subsidized through these states' new insurance exchanges are not covered. Overall, the drafters of the ACA believed that increasing coverage would not only improve the quality of life for many citizens but would also reduce both medical bankruptcies (the most common cause of bankruptcies in America) and job lock (the unwillingness to leave one job to take another because of fear of losing medical insurance).

The ACA establishes state-based insurance exchanges. These exchanges are online market places administered by either the states or the federal government at which individuals and small businesses may compare and purchase private insurance plans that have been preapproved. These Web sites are regulated, and the plans are comparable either

Table 1. Groups of Individuals Not Covered by the Affordable Care Act Essential Health Services

1. Illegal immigrants (although they still remain eligible for emergency medical services under provisions of the Emergency Medical Treatment and Active Labor Act)

2. U.S. citizens who are eligible for Medicaid but who are not enrolled in this program

3. U.S. citizens not otherwise covered but who choose to pay the annual penalty instead of purchasing insurance

4. U.S. citizens whose insurance premiums would cost more than $8 \%$ of their household income (they are exempt from paying the annual penalty)

5. U.S. citizens who live in states that opt out of the Medicaid expansion and who qualify for neither Medicaid coverage nor are subsidized through these states' new insurance exchanges

Adapted from information on Wikipedia. ${ }^{1}$ 
FIG. 2. Principal portions of the Affordable Care Act that may be of importance to caregivers of diabetes patients. Adapted from Mason ${ }^{5}$ and the American Diabetes Association. ${ }^{6}$

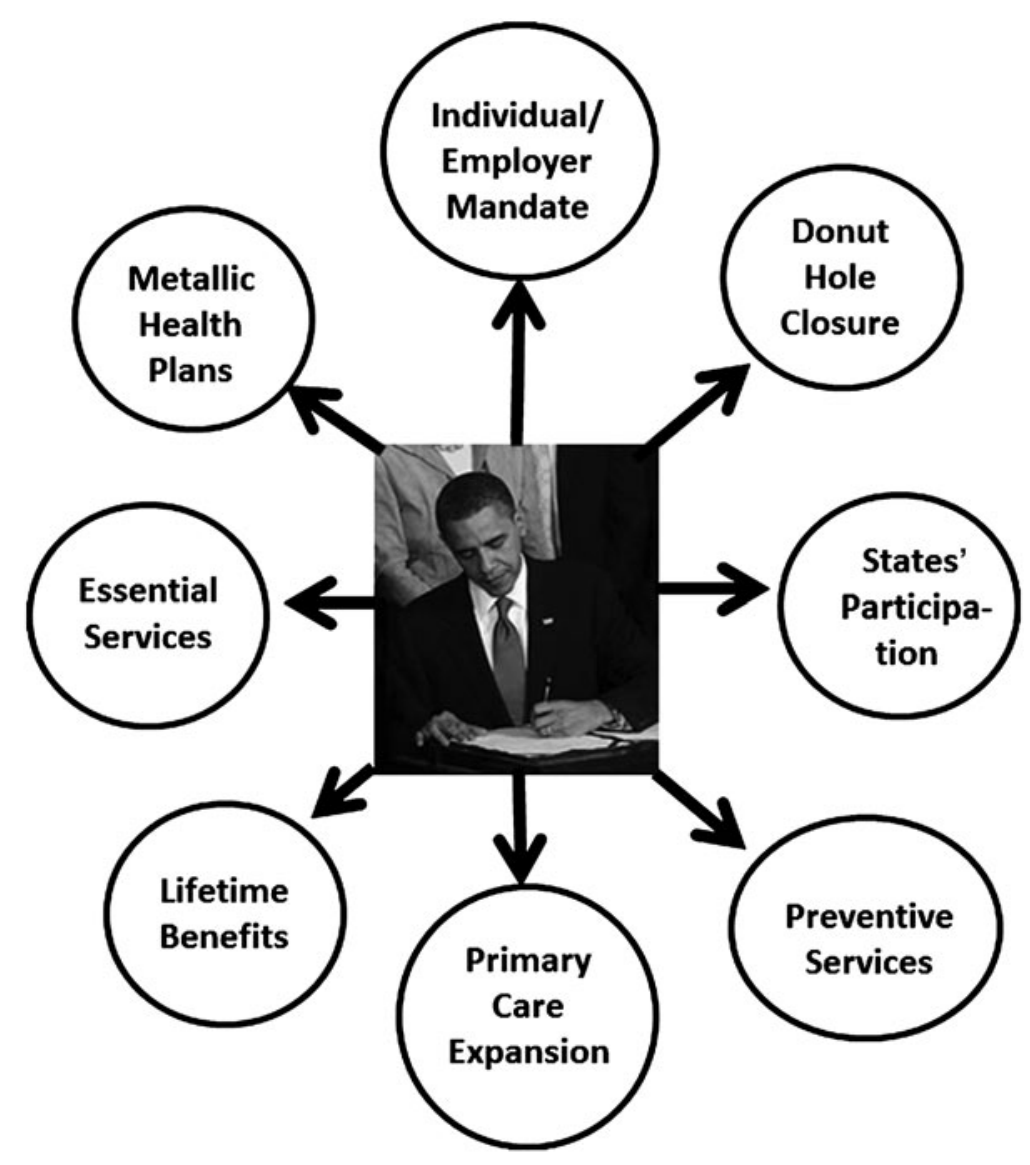

directly or by contacting a call-in center. Specific enrollment periods will be set to discourage individuals from delaying coverage until they become ill. Only approved insurance plans that meet specified standards will be allowed to be sold on the exchanges.

What are the standards that approved plans must meet? First, there is a ban on the ability to drop policyholders if they become sick. Second, there is also a ban on price discrimination on the basis of preexisting conditions or gender. Third, policies must permit children and dependents to remain on their parents' insurance plans until their $26^{\text {th }}$ birthday. Fourth, insurers are prohibited from imposing annual or lifetime caps coverage on essential benefits (Table 3 ).

TAble 2. 2014 Poverty Guidelines for the 48 Contiguous States and the District of Columbia

\begin{tabular}{cc}
\hline Persons in family/household & Poverty guideline \\
\hline 1 & $\$ 11,670$ \\
2 & 15,730 \\
3 & 19,790 \\
4 & 23,850 \\
5 & 27,910 \\
6 & 31,970 \\
7 & 36,030 \\
8 & 40,090
\end{tabular}

For families/households with more than eight persons, add $\$ 4,060$ for each additional person. Adapted from the Assistant Secretary for Planning and Evaluation. ${ }^{63}$

\section{Items Included in the ACA That Are Beneficial to Diabetes Patients}

\section{Medicare "donut hole" is closed}

One of the chief benefits of the ACA is a slow, inevitable closure of the infamous Medicare Part D "donut hole" between 2014 and 2020. ${ }^{7}$ The donut hole is a gap in prescription medication coverage that occurs once all deductibles and copayments have been met and once a $\$ 2,850$ ceiling on annual payments has been reached. At that point, policyholders may be responsible for $100 \%$ of prescription drug costs until a yearly cap on out-of-pocket expenses of $\$ 4,950$ has been achieved. A schematic representation of how the donut hole affects out of pocket costs is shown in Figure 3.

The donut hole principally affects seniors who are enrolled in Medicare Part D and who have incomes large enough to

\section{Table 3. Essential Health Services}

Hospitalizations

Some maternity and newborn care

Vision and dental care for children

Rehabilitative and habilitative services and devices

Ambulatory (outpatient care)

Pediatric care

Mental health and behavioral health treatment

Laboratory services and chronic care

Adapted from ObamaCare Facts. ${ }^{64}$ 


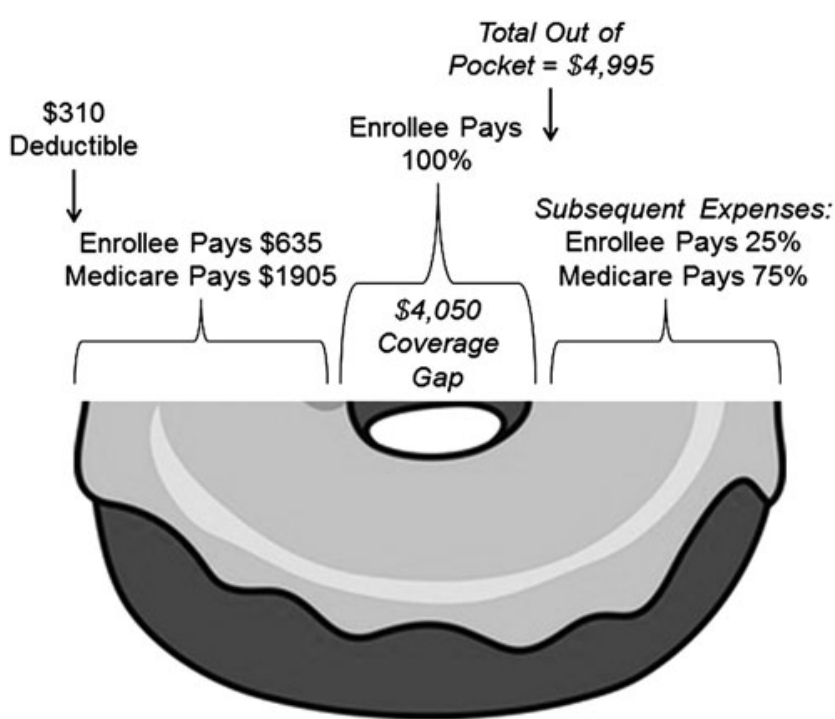

FIG. 3. Schematic representation of how out-of-pocket expenses attributable to the donut hole would work in a typical case. Adapted from the Society for Cardiovascular Angiography and Interventions. ${ }^{62}$

exclude them from low-income subsidies. Approximately $6 \%$ of such seniors achieve the donut hole threshold each year, but the threshold may be more rapidly achieved in patients with diabetes (Fig. 4). ${ }^{8}$ For example, one study from 2006 demonstrated that $41 \%$ of enrollees with diabetes in Medicare Part D achieved the donut hole threshold compared with $25 \%$ of participants without diabetes. ${ }^{9}$

Achieving the donut hole threshold may result in patients having to choose between paying for their medications or some other essential expense, such as food and lodging. Although federal programs initiated in 2010 have reduced copayments on medications that fall within the donut hole to $47.5 \%$ of the cost of brand-name drugs and $72 \%$ of the cost of generic drugs, the ACA will gradually reduce these costs to a standard $25 \%$ copayment by the year $2020 .^{10}$

As mentioned above, the copayment on covered generic and brand-name Medicare drugs will be reduced to $25 \%$ by the year 2020. The American Association of Retired Persons estimates that the reductions in copayments attributable to closure of the donut hole have already saved 6.1 million

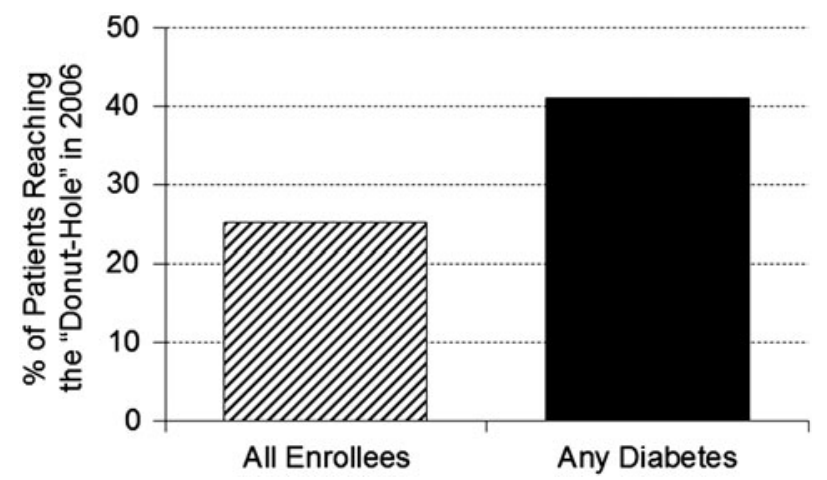

FIG. 4. Percentage of Medicare enrollees achieving the donut hole as of November 2006. Adapted from Zhang et al. ${ }^{9}$
Americans more than $\$ 5.7$ billion on drug costs by $2012 .^{11}$ This amounted to $\$ 706$ per beneficiary, on average, in 2012 alone, with American seniors saving a total of $\$ 435$ million on diabetes medications, $\$ 240$ million on lipid-lowering medications, and $\$ 138$ million on antihypertensive medications. These are all classes of medications that are used frequently by people with diabetes. Better still, the U.S. Government estimates that the cumulative average savings attributable to closure of the donut hole will total more than $\$ 5,000$ per Medicare beneficiary by the year 2022. ${ }^{12}$ One study found that the donut hole coverage gap disproportionately affected seniors with diabetes, inhibiting the use of high-cost prescription drugs (e.g., antipsychotics) by as much as $18 \%$ and decreasing utilization of low-cost drugs (e.g., angiotensinconverting-enzyme inhibitor inhibitors) from $3 \%$ to $5 \% .^{13}$ The gradual disappearance of the donut hole over the next few years should reduce this disparity and improve the health and lifestyle of people with diabetes.

\section{Nonexclusion of preexisting conditions}

Under provisions of the ACA, health insurance coverage cannot be denied to patients with preexisting conditions that might have previously excluded them from care. Although there is disagreement over how many people with diabetes this provision affects, all workers with type 1 diabetes, and many with type 2 diabetes, would probably be excluded from purchasing healthcare coverage on the individual marketplace because of preexisting disease exclusions. The U.S. Government has asserted that preexisting disease exclusions likely affect between 50 and 129 million adults (i.e., up to $50 \%$ of adults). ${ }^{14}$ Others have asserted that this figure is too high because some people with preexisting diseases who meet criteria for exclusion are already covered by group health insurance plans provided by their employers or have been able to successfully negotiate for privately held health insurance plans. ${ }^{15}$ Nevertheless, Greenberg ${ }^{16}$ on Politfact.com adjudges President Obama's comment that "up to 50\%" of adults could be affected by preexisting disease exclusions to be "mostly true." However, Greenberg points out that many people are affected by preexisting disease exclusions even if they currently possess health insurance from their employer because of "job lock."

Job lock is the phenomenon that occurs when workers are reluctant to leave their current occupation in favor of one that they might prefer because of a fear of being unable to obtain (or afford) health insurance once they leave the protection of their existing group health coverage. ${ }^{17}$ There is a consensus that job lock is a real phenomenon, with one study finding that older male workers with retiree health benefits are $68 \%$ more likely to retire than those who do not. ${ }^{18}$ A recently released report from the Congressional Budget Office estimates that 2.5 million workers will take advantage of the ACA's guaranteed availability of healthcare coverage to leave their current place of work by $2024{ }^{19}$ Although it is difficult to accurately estimate the effects of job lock, per se, in people with diabetes, one study did attempt to estimate the economic disadvantages attributable to diabetes. ${ }^{20}$ In that study, compared with peers who did not have diabetes, people with diabetes had a $6 \%$ higher dropout rate from high school, a 10\% reduction in the chance of finding a job, a reduced likelihood of attending college, and a lifetime reduction in earnings of more than $\$ 160,000$, some of 
which is likely attributable to job lock. Because the ACA will eliminate preexisting disease exclusions and will result in widely available healthcare coverage (and freedom from job lock) for people with diabetes, it is probable that this health disparity will be significantly reduced by the ACA.

\section{Prohibition on limiting lifetime/annual benefits}

The ACA prohibits health plans from putting a lifetime dollar limit on most benefits. Effective September 23, 2010, a group health plan may not establish any lifetime dollar limits on the value of "Essential Health Benefits" for any individual under the group health plan. However, a group health plan may impose lifetime limits on the dollar value of specifically covered benefits that are not "essential health benefits" to the extent that those limits are not otherwise prohibited under federal or state law.

Essential health care benefits include, but are not limited to, doctor office visits, hospital care, and prescriptions. Before the ACA, many health plans could limit how much they would spend to cover health benefits each year ("annual dollar limit"). Many health plans could also set a "lifetime dollar limit" on how much they would spend to cover health benefits for the entire time that a person was enrolled in a plan. Anyone who incurred healthcare costs higher than these limits would have to pay the amount that was over the limit.

A health plan cannot limit the total amount it will spend to cover benefits during the entire time an individual is enrolled in the plan. This new law applies to all employer-based group health plans ("group coverage") and all individual insurance coverage purchased for an individual and/or his or her family. As such, the ACA phases out annual dollar limits a health plan places on most of the benefits. Annual limits will be eliminated entirely in 2014. This law applies to all group coverage and individual coverage purchased after September 23,2010 . However, this new law does not apply to individual coverage purchased on or before March 23, 2010, known as "grandfathered"' individual coverage. Each health plan must state in its provided materials if it is a grandfathered plan. ${ }^{21}$

\section{Permission to stay on parents' insurance plans}

Nearly all young people can stay on their parents' plan until 26 years of age, even if they're married, financially independent, and no longer live with their parents. Young adults who are offered coverage through their own jobs can choose that plan or remain with their parents' plan if they prefer. What if the parents don't have insurance or are buying subsidized coverage at an exchange that is cheaper than the young adult staying on their parents' insurance? Almost anyone can shop for coverage on the health insurance marketplace, but the young adult will only be eligible for subsidies to reduce the cost of coverage under certain circumstances. If the parents don't claim the young adult as a dependent on their tax return and the young adult's own income is below $400 \%$ of the federal poverty level, he or she could be eligible for premium tax credits on the exchange. But, if the parents do claim the young adult as a dependent, his or her eligibility for subsidies will be based on the family's income, not just the young adult's income. In addition, if the young adult plans to become pregnant while on her parents' plan, she should check to make sure maternity benefits are covered. Although most group plans must provide maternity coverage for employees and their spouses by law, children aren't protected by this law, and employers don't always provide coverage. ${ }^{22}$

\section{Free preventive services}

As shown in Table 4, the ACA provides designated preventive services at no cost to the enrollee. Although certain of these preventive maneuvers can be interpreted as specifically benefitting individuals with diabetes (such as pneumococcal and influenza vaccines, depression screening, preventive tooth care for children, and prepregnancy contraception), most of these items are not diabetes specific. Although free preventive services represent a boon for Americans in general, people with diabetes are especially poised to benefit. Much of this benefit is derived from improved coverage of screening services to increase case detection rates and to identify diabetes (or prediabetes) at a stage when it is easier to treat and more amendable to lifestyle change. According to the Centers for Disease Control and Prevention, the ACA covers services that include type 2 diabetes screening, diet counseling, and blood pressure screening. In addition, Medicare also covers diabetes screening tests to identify beneficiaries with diabetes or those who are at high risk of developing diabetes (i.e., persons with prediabetes). Other Medicare preventive benefits such as diabetes self-management training and medical nutrition therapy are offered in an attempt to support enrollees in self-care and in making lifestyle changes to prevent or minimize development of the comorbidities and complications of diabetes. Medicare Advantage plans (a type of Medicare health plan offered by a private company that contracts with Medicare to provide the insuree with Part A and Part B benefits) have additionally identified 36 Special Needs Plans focused on chronic disease care. These plans are being offered for Medicare patients with diabetes, with benefits that include (1) health education for all beneficiaries on ways to prevent diabetes, (2) extra self-care skills training for those with diabetes, and (3) focused disease management programs that provide care coordination and inhome monitoring to prevent development of comorbidities and complications of diabetes. ${ }^{23}$ According to the American Association of Retired Persons, an estimated 8 million Americans who were enrolled in Medicare used \$34.1 million in free prevention services in $2012 .^{11}$

\section{Prevention of type 2 diabetes programs}

The ACA authorized the creation of the National Diabetes Prevention Program at the Centers for Disease Control and Prevention in order to "eliminate the preventable burden of diabetes." According to the Centers for Disease Control and Prevention, the National Diabetes Prevention Program is designed to bring to communities evidence-based lifestyle change programs for preventing type 2 diabetes. It is based on the Diabetes Prevention Program research study supported by the National Institutes of Health.

The promise of the National Diabetes Prevention Program is that, with full funding to initiate the program, adults with prediabetes across the United States could access evidence-based diabetes prevention programs in their local communities. As of March 10, 2014, the Centers for Disease Control and Prevention's Web site showed that community-based organizations in 48 states are in the process of achieving recognition for their diabetes prevention programs. $^{24}$ 
Table 4. Preventative Services Covered by the Affordable Care Act

That May Particularly Benefit Individuals with Diabetes

\begin{tabular}{|c|c|}
\hline Population & Preventative services \\
\hline Children & $\begin{array}{l}\text { 1. Depression screening for adolescents } \\
\text { 2. Dyslipidemia screening for children at higher risk of lipid disorders } \\
\text { 3. Fluoride chemoprevention supplements for children without fluoride in their water source } \\
\text { 4. Height, weight, and body mass index measurements for children } \\
\text { 5. Immunization vaccines for children from birth to age } 18 \text {, to include diphtheria, tetanus, pertussis, } \\
\text { Haemophilus influenzae type b, hepatitis A, hepatitis B, human papillomavirus, inactivated poliovirus, } \\
\text { influenza, measles, mumps, rubella, Meningococcus, Pneumococcus, rotavirus, and varicella } \\
\text { 6. Obesity screening and counseling } \\
\text { 7. Oral health risk assessment for young children }\end{array}$ \\
\hline Women & $\begin{array}{l}\text { 1. Anemia screening on a routine basis for pregnant women } \\
\text { 2. Food and Drug Administration-approved contraceptive methods, sterilization procedures, and patient } \\
\text { education and counseling, as prescribed by a healthcare provider for women with reproductive capacity } \\
\text { 3. Gestational diabetes screening for women } 24-28 \text { weeks pregnant and those at high risk of developing } \\
\text { gestational diabetes } \\
\text { 4. Osteoporosis screening for women over } 60 \text { years of age depending on risk factors } \\
\text { 5. Tobacco use screening and interventions for all women }\end{array}$ \\
\hline All adults & $\begin{array}{l}\text { 1. Abdominal aortic aneurysm one-time screening for men of specified ages who have ever smoked. } \\
\text { 2. Aspirin use to prevent cardiovascular disease for men and women of certain ages } \\
\text { 3. Blood pressure screening for all adults } \\
\text { 4. Cholesterol screening for adults of certain ages or at higher risk for cardiovascular disease } \\
\text { 5. Depression screening for adults } \\
\text { 6. Diabetes (type 2) screening for adults with high blood pressure } \\
\text { 7. Diet counseling for adults at higher risk for chronic disease } \\
\text { 8. Immunization vaccines for adults, to include influenza, Pneumococcus } \\
\text { 9. Obesity screening and counseling for all adults } \\
\text { 10. Tobacco use screening for all adults and cessation interventions for tobacco users }\end{array}$ \\
\hline
\end{tabular}

Adapted from HealthCare.gov ${ }^{56}$

\section{Diabetes report cards}

A rarely discussed aspect of the ACA is the incorporation of a bill from 2009 into the language of the act. "The Catalyst to Better Diabetes Care Act" directs the U.S. Department of Health and Human Services and the Centers for Disease Control and Prevention to enhance diabetes surveillance and quality standards across the country. ${ }^{23}$ This provision requires the Secretary of the U.S. Department of Health and Human Services to prepare a publicly available national diabetes report card for each state every 2 years. These report cards must include statewide results related to the diagnosis of diabetes and prediabetes, as well as information about preventive care practices and quality of care indicators. ${ }^{5}$ The provision also directs the U.S. Department of Health and Human Services and the Institute of Medicine to study the impact of diabetes on the practice of medicine and to identify the level of diabetes education that should be required prior to practitioner licensure and board certification. ${ }^{25}$ It is hoped that these report cards will lead to an improved national focus on issues of obesity, nutrition, and exercise, as well as comprehensive health risk assessments and personalized prevention plans. ${ }^{26}$

For these Report Cards to be useful, however, there will need to be a surfeit of practical information provided in a similar format by each state. Because there will likely be political pressures for states to downplay or obfuscate problems that exist within their individual programs, standardization of reporting will be essential. In addition, reporting problems could become magnified to the extent that federal matching funds for Medicaid become dependent on statewide diabetes outcomes. As such, how the Diabetes Report Cards will work out in actual practice remains to be determined.

\section{Plan types, including coverage for catastrophic medical expenses}

As anticipated, there are several plans available from which the diabetes patient may choose (Table 5). The "metallic" plans (bronze, silver, gold, and platinum) reflect an effort to share costs between insurer and insured. For people below $400 \%$ of the federal poverty level, discounts will be available. As of 2013, for the lower 48 states and the District of Columbia, the income level was $\$ 45,960$ for singles, $\$ 62,040$ for a married couple with no children, and $\$ 94,200$ for a family of four. These plans do not include the catastrophic coverage option. Everyone's out-of-pocket maximums will be the same (regardless of the plan they choose) unless each state decides to change the limits for higher plans (such as California has done with Platinum plans). As it now stands, regardless of the plan that is chosen, the maximum out-of-pocket cost for healthcare, aside from insurance premiums, will be the federal limits for highdeductible healthcare plans. In 2014, that limit was $\$ 6,350$ for singles and $\$ 12,700$ for families. Analysts expect young adults to gravitate toward the bronze and catastrophic plans, which are the lowest-cost options. Both the bronze and the catastrophic plans cover basic preventative health services, including cholesterol tests, immunizations, and screenings for depression and alcoholism. Both 
Table 5. Available Health Plans

\begin{tabular}{|c|c|c|}
\hline Plan type & Cost share/premiums & Comments \\
\hline Bronze & $40 \% /$ low & $\begin{array}{l}\text { Typically offer the lowest premiums but the least coverage } \\
\text { of the four metallic plan levels. Good for people who do not } \\
\text { plan to use medical services }\end{array}$ \\
\hline Silver & $30 \% /$ medium-low & $\begin{array}{l}\text { Good for individuals and families who use a few basic health services } \\
\text { but don't have any serious health problems }\end{array}$ \\
\hline Gold & $20 \% /$ medium & $\begin{array}{l}\text { Good for families that don't want to worry about healthcare costs } \\
\text { stopping them from getting the care they need }\end{array}$ \\
\hline Platinum & 10\%/high & $\begin{array}{l}\text { Good for anyone who wants "the best coverage" and also for those } \\
\text { who are sick or who have dependents who are likely to use costly } \\
\text { health services }\end{array}$ \\
\hline Catastrophic & $0 \% /$ low, high-deductible & $\begin{array}{l}\text { Only for }<30 \text { years of age or who cannot find coverage for }<8 \% \\
\text { of their income }\end{array}$ \\
\hline
\end{tabular}

Adapted from Adleman. ${ }^{57}$

also cover, to varying degrees, all categories of essential health services. ${ }^{27}$

1. Bronze plans split covered expenses 60:40. Bronze plans are the least expensive because insurers pay only $60 \%$ of covered health expenses, and the policyholder must cover the other $40 \%$. Bronze plans also have the most basic benefits and the most limited networks of doctors and hospitals. This is a good choice for those individuals who don't plan on using many medical services. Many low-income Americans may qualify for no cost or very low-cost bronze plans, but out-of-pocket expenses can be considerably higher with a bronze plan compared with a silver plan, which may cost only slightly more.

2. Silver plans split covered expenses 70:30. Silver plans are the "marketplace"" standard, meaning that premium caps are based on the cost of silver plans. A silver plan on the marketplace can't cost more than $9.5 \%$ of an individual's income if the individual earns less than $400 \%$ of the federal poverty level. The less you make, the lower the premium cap is. A silver-level plan is a good choice for individuals and families who use a few basic health services but don't have any serious health problems.

3. Gold plans split covered expenses 80:20. Gold plans cost a little more, but the lower deductibles and reduced out-of-pocket cost sharing means that policyholders won't have to worry about healthcare costs inhibiting them or their families from receiving the care they need. Even if the policyholder's premium is subsidized, he or she will have to pay more to make up the difference if he or she wants a gold plan.

4. Platinum plans split covered expenses 90:10. Platinum plans have the lowest out-of-pocket health care costs but the highest monthly premiums. This is the right choice for individuals who want "the best coverage" for themselves and their family. It is a smart buy for those who are sick or who have dependents who are likely to use costly health services. Even if your premium is subsidized, the policyholder will have to pay more to make up the difference if he or she wants a platinum plan.
5. Catastrophic coverage. Catastrophic coverage is available to some people under 30 years old and those with hardship exemptions. Catastrophic plans only cover the bare minimum health benefits and have a very limited network. Policyholders will have high out-of-pocket costs and a high deductible, but this type of plan will protect them in a worstcase scenario and will ensure that they avoid paying the shared responsibly fee for not having health coverage. ${ }^{28}$

Premiums for catastrophic plans are about $20 \%$ lower, on average, than prices for other health plans available in the ACA exchanges. However, unlike the metallic plans, catastrophic plans don't offer potential discounts through tax subsidies. People older than 30 years of age who shop for health insurance in the Obamacare exchanges are usually required to choose a more comprehensive plan but may buy a catastrophic plan under one of the law's many exemptions. The ACA's catastrophic plans cover three annual primary care visits and preventive services at no cost, including disease screenings and vaccinations. Beyond that, the patient pays all medical expenses out of pocket up to a steep deductible, generally $\$ 6,350$ for individuals and $\$ 12,700$ for families.

\section{Items Included in the ACA That Are of Concern to Diabetes Patients}

\section{Over-reliance on high-deductible insurance plans}

One aspect of the ACA that gets little media coverage is that it will likely increase costs to the individual in the short run. For example, a family of four from New Mexico with adults in their 50s who earn $\$ 96,000$ a year will just barely not qualify for the allowances for a subsidy on the purchase of their healthcare coverage. In that case, health insurance premiums will cost $\$ 9,602$ per year for a silver plan, and this plan allows for the expenditure of an additional $\$ 12,700$ in deductibles and copayments during the course of each year. Therefore, this family may end up spending as much as $\$ 22,300$, or $23 \%$ of their gross income, over the course of the year. ${ }^{29}$ This scenario exemplifies America's relatively rapid transition to a high-deductible insurance system under the ACA that may present a significant financial burden to middle-income wage earners who must grapple with serious disease within their families from year to year.

Because benefits and coverage will vary from plan to plan, patients with diabetes will need to shop carefully when 


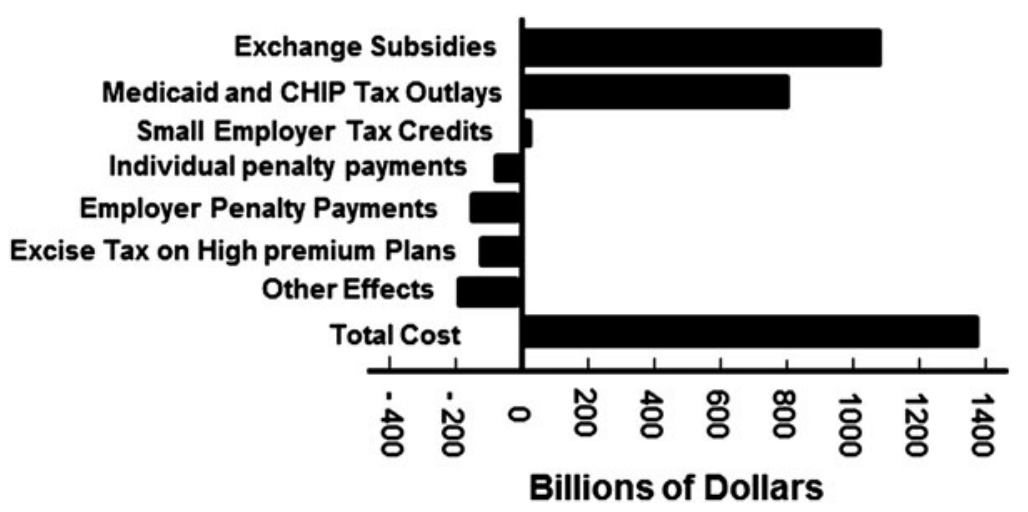

FIG. 5. Estimated budget of the Affordable Care Act from 2015 to 2024. Bars to the left of zero offset the expenses to the right of zero. These estimates will change as experience with the Affordable Care Act increases. CHIP, Children's Health Insurance Program. Adapted from the Congressional Budget Office. ${ }^{59}$ selecting among platinum, gold, silver, and bronze plans. If available, plans that offer copayment-free or deductible-free coverage of diabetes-related medications, supplies, and medical visits are likely to be preferable to those that do not.

\section{Costs to individuals and the federal government}

The Congressional Budget Office predicts that health insurance subsidies under the ACA will total a little more than $\$ 1$ trillion over the next 10 years (Fig. 5). Most of the budgetary effects of the ACA's coverage provisions will stem from the subsidies for insurance purchased through the exchanges and from increased costs for Medicaid. That additional spending will be partially offset by penalty payments made by individuals and employers (Table 6), by additional revenues resulting from the excise tax on high-premium insurance plans, and by the effects on income and payroll tax revenues and associated outlays stemming from a reduction in employment-based insurance coverage.

\section{Individual costs}

The Congressional Budget Office estimates that the average cost of individual policies for the second-lowest-cost silver plan in the exchanges (the benchmark for determining exchange subsidies) is about $\$ 3,800$ in 2014 . That estimate represents a national average, and it reflects the Congressional Budget Office's projections of the age, sex, health status, and geographic distribution of those who will obtain coverage through the exchanges in 2014. That benchmark premium is projected to rise slightly in 2015 , to about $\$ 3,900$, and then to rise more rapidly thereafter, reaching about $\$ 4,400$ in 2016 and about $\$ 6,900$ in 2024 . Thus, premiums are projected to increase by about $6 \%$ per year, on average, from 2016 to 2024 . However, there is not one specific cost for any given individual or an individual's family. The cost for an individual or family is dependent on several factors, in-

Table 6. Penalty for No Insurance "INDIVIDUAL Mandate"

Year Penalty

$2014 \$ 95$ per person per year or $1 \%$ of your income

$2015 \$ 325$ per person per year or $2 \%$ of your income

$2016 \$ 695$ per person per year or $2.5 \%$ of your income

2017 Tax penalty will increase by the rate of inflation going forward, or $2.5 \%$ of the individual's income

Adapted from ObamaCare Facts. ${ }^{58}$ cluding (1) the annual household income, (2) the number and ages of the individuals to be insured, (3) the state in which the insured person lives, and (4) whether or not employer coverage is available. In order to determine a specific individual's cost, there are several calculators online that facilitate the calculation (e.g., http://laborcenter.berkeley .edu/healthpolicy/calculator/). From this calculation, the yearly cost for a family of one to four usually ranges from zero to $\$ 6,000$, depending on the amount of federal supplement. $^{30}$

\section{Penalty for nonparticipation}

One of the key parts of ACA is the "individual mandate." 31 Originally proposed by the Heritage Foundation in 1989, the individual mandate requires that all eligible Americans have at least basic health coverage. The individual mandate is officially part of the shared responsibly provision and is called an "individual shared responsibility fee." The fee is administered as follows: if the individual doesn't have insurance or hasn't obtained an exemption by April 30, 2014, he or she will be charged a fee on his or her year-end taxable income for every month he or she doesn't have insurance. If the individual has coverage for at least 1 day in that taxable month, then he or she doesn't owe the payment for that month. The penalty will be applied to his or her year-end federal modified adjusted gross income for each month he or she doesn't have health insurance or an exemption. The fee for not having insurance in 2014 is $\$ 95$ per year for an adult and $\$ 47.50$ per year for a child (up to $\$ 285$ for a family) or $1 \%$ of your taxable income, whichever is greater. A single person earning more than $\$ 19,650$ would not qualify for the $\$ 95$ penalty $(\$ 19,650$ $\$ 10,150=\$ 9,500 \times 1 \%=\$ 95)$. So the $1 \%$ penalty is the standard that will apply in most cases. For example, for a single person whose modified adjusted gross income is $\$ 35,000$, the penalty would be $\$ 249(\$ 35,000-\$ 10,150=\$ 24,850 \times 1 \%=\$ 249)$. The tax penalty (shared responsibility fee) for not having insurance is paid on an individual's federal income taxes at the end of the year. If his or her taxable income is below $133 \%$ of the federal poverty level, then he or she is exempt from this tax. The tax penalty will increase in the subsequent years.

If the individual is uninsured for just part of the year, 1/12 of the yearly penalty applies to each month he or she is uninsured. The total penalty for the taxable year cannot exceed the national average of the annual premiums of a bronze-level health insurance plan offered through the health insurance marketplaces. The maximum penalty per family is capped at no more than $300 \%$ of the minimum 
penalty (e.g., $\$ 695 \times 300 \%=\$ 2,085$ ). Children under 18 years of age are assessed at $50 \%$ of the minimum penalty. The penalty is prorated for the number of months they are without health insurance, although there is no penalty for a single gap in coverage of less than 3 months in a year. Health insurance plans will provide proof of coverage for their enrollees. ${ }^{28}$

\section{Variable acceptance of expanded Medicaid by states}

The expansion of Medicaid under the ACA is one of the chief mechanisms being used to expand health insurance coverage. Prior to the ACA, Medicaid eligibility varied state by state. Under the ACA, Medicaid eligibility is expanded to those earning less than $138 \%$ of the federal poverty level nationwide, with the federal government covering between $90 \%$ and $100 \%$ of the costs of this expansion over the next 10 years. Additionally, federal subsidies are available to people earning less than $400 \%$ of the federal poverty level. Although upholding the mandate for individuals to purchase health insurance, in June 2012, the U.S.
Supreme Court ruled that the expansion of Medicaid under the ACA was unconstitutionally coercive of states, thereby allowing states to opt out of the Medicaid expansion. ${ }^{29,32}$ This led to the new concept of the "coverage gap," describing people who earn too much to qualify for state-specific Medicaid in states who opt out of Medicaid expansion and yet who are too poor to purchase even heavily subsidized health insurance. States opting out of the Medicaid Expansion are shown in Figure 6.

As an example of the coverage gap, in North Carolina, 319,000 individuals will be denied health insurance because of the state's refusal to expand Medicaid, leaving a total 1.2 million people uninsured by $2016 .{ }^{33}$ In addition, $86 \%$ of poor, uninsured, nonelderly adults will fall into the coverage gap as of 2014. These people are eligible for neither Medicaid nor exchange subsidies. If fully implemented by all states, the expansion of Medicaid as outlined in the ACA would provide healthcare coverage for 17 million Americans with a net budget gain to states of $\$ 304$ billion between 2014 and 2023. ${ }^{34}$ Another issue with the ACA is the coverage of minority ethnic groups. To date, the largest majority signing up

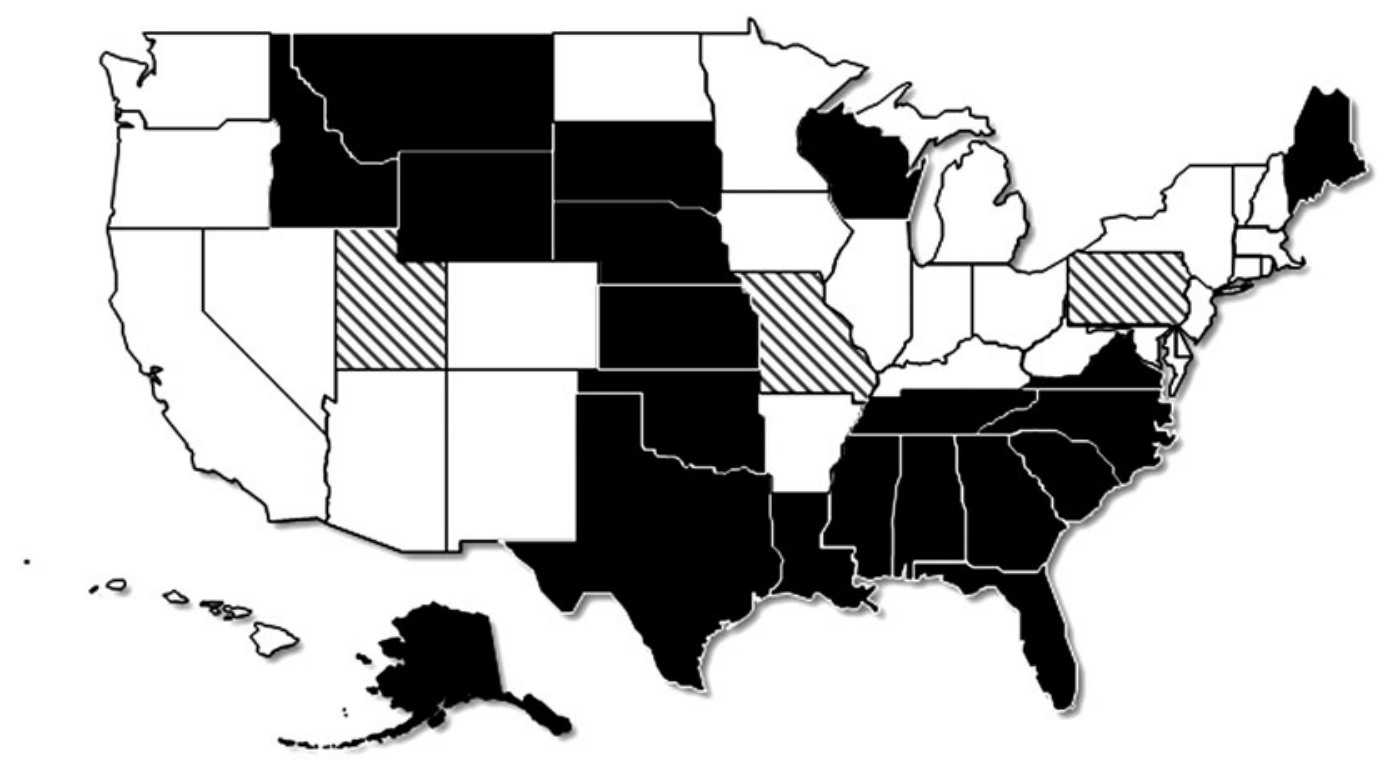

\begin{tabular}{|c|c|c|c|}
\hline $\begin{array}{c}\text { States Opting In for } \\
\text { Expansion of Medicaid as of }\end{array}$ & Maryland & States Opting Out of & North Carolina \\
March, 2014 & Massachusetts & Medicaid Expansion as of & Oklahoma \\
Mrizona & Minnesota & March, 2014 & South Carolina \\
Arkansas & New & Alabamath Dakota \\
California & Nevada & Alaska & Tennessee \\
Colorado & New Jersey & Florida & Texas \\
Delaware & New Mexico & Georgia & Virginia \\
District of Columbia & NewYork & Idaho & Wisconsin \\
Hawaii & North Dakota & Kansas & Wyoming \\
Illinois & Ohio & Louisiana & States Still Considering \\
Indiana & Oregon & Maine & Medicaid Expansion as of \\
lowa & Rhode island & Mississippi & March, 2014. \\
Kentucky & Vermont & Montana & Missouri \\
& Washington & Nebraska & Pennsylvania \\
& West Virginia & & Utah \\
\hline
\end{tabular}

FIG. 6. The 27 white-filled states depict those that have opted to expand Medicaid in response to the Affordable Care Act. The 20 black-filled states have opted not to expand Medicaid in response to the Affordable Care Act. The three hatched states are still considering expanding Medicaid in response to the Affordable Care Act. Adapted from the Kaiser Family Foundation ${ }^{6,61}$ and Dickman et al. ${ }^{32}$ 


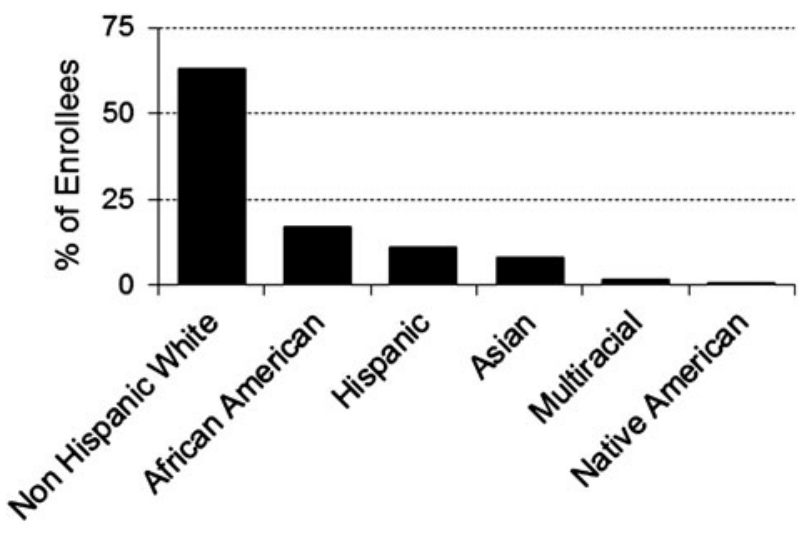

FIG. 7. Racial and ethnic distribution of new healthcare enrollees from 36 states using the Federal Market Place. Adapted from Millman. 1

for the ACA are non-Hispanic whites (Fig. 7). Additional efforts need to be made to reach minorities that are underrepresented in the ACA.

Although the exact effects of not expanding Medicaid on the health of patients with diabetes is not yet known, several studies have shown that the lack of access to basic health insurance increases mortality. ${ }^{35,36}$ The study by Sommers et al. ${ }^{36}$ found that an expansion of Medicaid eligibility in three states was associated with a significant reduction in the risk of overall mortality at 5 years of follow-up, especially among adults between the ages of 35 and 64 years. In the Oregon Health Insurance Experiment, Medicaid coverage was expanded to nearly 30,000 citizens for 1 year based on a lottery, and comparison was made to approximately 29,000 matched individuals who did not receive such coverage. The investigators found that people with Medicaid coverage exhibited significantly higher healthcare utilization, lower out-of-pocket medical expenditures and medical debt, and better self-reported health than the control group. ${ }^{37}$ Specifically, they noted a $30 \%$ increase in the probability of having a hospital admission, a $15 \%$ increase in the probability of taking any prescription drugs, and a $35 \%$ increase in the probability of having an outpatient visit. A subsequent article showed that after 2 years, no improvements in clinical outcomes could be demonstrated among those who received Medicaid and those who did not, but detection of new diabetes cases was increased among those who received expanded coverage. ${ }^{38}$

Given that the ACA is largely based on the comprehensive health care reform that was introduced in the state of Massachusetts in 2006, the experience in Massachusetts may be indicative of results and outcomes to expect from the ACA. One recent report demonstrated that among adults 20-64 years of age and compared with a matched control group from other states, all-cause mortality was reduced in Massachusetts after implementing healthcare reform. ${ }^{39}$ Specifically, all-cause mortality was reduced by $2.9 \%$, and absolute death rates were decreased by 8.2 deaths per 100,000 individuals. It is impressive that observed gains were largest in those counties with lower incomes and with higher rates of uninsured people prior to the institution of healthcare reform. These promising results provide an initial proof of concept for the idea that improving health insurance coverage can improve the overall health of a population.

\section{Confusion over coverage for supplies and durable medical equipment}

Aside from the large prescription drug costs associated with diabetes care, diabetes is a device- and supply-intensive disease. Some recurring expenses in diabetes unrelated to prescription drugs include the costs of capillary blood glucose meters and test strips, insulin syringes, finger-lancing devices and lancets, insulin pumps and the infusion sets that accompany them, and continuous glucose monitors and the sensors that work with them. The American Diabetes Association estimates that $12 \%$ of the annual $\$ 245$ billion national cost of diabetes, or $\$ 29$ billion, is attributable to these expenses. ${ }^{40}$ The cost of diabetes supplies to individuals is estimated to be between $\$ 350$ and $\$ 900$ per month, with the cost of an insulin pump adding another $\$ 2,500$ per year. ${ }^{41} \mathrm{Un}$ fortunately, the ACA provides few details about whether or not these expenses will be covered and whether or not these expenses will be applied before or after deductibles are met. According to the National Conference of State Legislatures, ${ }^{5}$ laws in 42 states already require most state-regulated insurance to cover treatment for diabetes, including self-management training, supplies, and equipment (such as insulin pumps, test strips, and meters). The ACA includes a provision that "standard benefit packages" sold through health benefit exchanges beginning in 2014 may be reexamined to determine if these plans are to include benefits beyond what is considered "standard.", Unfortunately, the definition of "standard benefits" has not yet been established by the U.S. Department of Health and Human Services, but it seems obvious that these expenses will need to remain manageable for individuals if diabetes treatment goals are to be met by a majority of people.

\section{Increased tax burden for high wage earners}

Several changes took effect at the beginning of 2013 that may impact an individual's income taxes. First, a change in the rules concerning deductible medical expenses (if a taxpayer is itemizing deductions) may affect all taxpayers. Only medical expenses that exceed $10 \%$ of an individual's adjusted gross income will be allowed as a deduction. (Taxpayers who are 65 years of age or older in 2013 still have a medical deduction floor of $7.5 \%$.) This change will affect all those who itemize. ${ }^{42}$

Second, there is an additional Medicare tax increase for high wage earners. As of 2013, high wage earners will incur a $0.9 \%$ increase in payroll taxes (officially, the Medicare hospital tax). Anyone making a gross income of $\$ 200,000$ or more will have that extra amount taken directly from his or her paycheck. This tax also applies to couples who jointly make $\$ 250,000$ or more. However, if a married couple filing jointly is making $\$ 150,000$ a person (for a total of $\$ 300,000$ ), an employer will not withhold the extra tax from payroll because it wouldn't know the spouse's income or that the couple was going to be over the threshold. So, if the $0.9 \%$ wasn't already withheld through payroll deductions, that couple would need to pay the extra $0.9 \%$ when taxes are due. Those individuals whose incomes put them above the threshold will pay this tax on the difference. Therefore, an individual who makes $\$ 250,000$ a year will pay the extra $0.9 \%$ marginal tax on only $\$ 50,000$ of his or her earnings. Third, for the tax year 2013 (which was due in April 2014), high earners incurred an 
additional $3.8 \%$ tax on their investment income. This tax only applies to people earning above $\$ 200,000$ individually or $\$ 250,000$ as a married couple filing jointly. However, unlike the payroll tax above, this tax is based on modified adjusted gross income. In contrast, the $0.9 \%$ payroll tax is based on gross income before deductions, whereas the investment tax is based on how much he or she made after adjusting for state taxes and additional deductions. Effectively, this means that the income threshold for this tax is higher than for the $0.9 \%$ payroll tax. ${ }^{43}$

\section{Small companies with fewer than 50 employees not covered by employer mandate}

The employer mandate is officially part of the Employer Shared Responsibility provision. Under the ACA, the federal government, state governments, insurers, employers, and individuals are given shared responsibility to reform and improve the availability, quality, and affordability of health insurance coverage in the United States. The annual employer mandate fee is a per-employee fee for employers with over 50 full-time equivalent employees who don't offer health coverage to fulltime employees. There are several provisions of this mandate. The employer mandate fee is officially referred to as a "shared responsibility payment," as the fee will help fund marketplace subsidies and to compensate for unreimbursed emergency healthcare provided to the uninsured (Table 7).

The ACA employer mandate/employer penalty, originally set to begin in 2014, will be delayed until 2015/2016. The ACA "employer mandate" is a requirement that all businesses with more than 50 full-time employees provide health insurance for their full-time employees, or else pay a monthly "Employer Shared Responsibility Payment" penalty on their federal tax return. Small businesses with 50-99 full-time employees will need to start insuring workers by 2016 . Those with 100 or more employees will need to start providing health benefits in 2015. Healthcare tax credits have been retroactively available to small businesses with 25 or fewer full-time employees since 2010.

Table 7. Stipulations of the Employer Mandate

The employer mandate is based on full-time equivalent employees, not just full-time employees.

The fee is based on whether or not insurer offers affordable health insurance to his or her employees that provide minimum value (explained below).

The annual fee is $\$ 2,000$ per employee if insurance isn't offered (the first 30 full-time employees are exempt).

If at least one full-time employee receives a premium tax credit because coverage is either unaffordable or does not cover $60 \%$ of total costs, the employer must pay the lesser of $\$ 3,000$ for each of those employees receiving a credit or $\$ 750$ for each of its full-time employees total.

The fee is a per-month fee due annually on employer federal tax returns starting in 2015 for small businesses with 100 or more full-time equivalent employees (2016 for those with 50-99 full-time equivalent employees). The per-month fee is $1 / 12$ of the $\$ 2,000$ or $\$ 3,000$ per employee.

Unlike employer contributions to employee premiums, the Employer Shared Responsibility Payment is not tax deductible.

\section{Lack of provider availability (endocrinology and primary care)}

Although primary care is fundamental to health system performance, the United States has undervalued and underinvested in primary care for decades. This deficiency is particularly important for people with diabetes who depend upon primary care for the majority of their treatment. The ACA will begin to address the neglect of America's primary care system. This law includes numerous provisions for improving primary care: temporary increases in Medicare and Medicaid payments to primary care providers, support for innovation in the delivery of care, with an emphasis on achieving better health outcomes and patient care experiences, enhanced support of primary care providers, and investment in the continued development of the primary care workforce. People who have access to a regular primary care physician are more likely than those who do not to receive recommended preventive services and timely care for medical conditions before they become more serious and more costly to treat. Having a regular doctor is also associated with fewer preventable emergency department visits and fewer hospital admissions, as well as with greater trust in and adherence to physicians' treatment recommendations. Among low-income patients, access to primary care is associated with better preventive care, better management of chronic conditions, and reduced mortality. In geographic areas where there are higher levels of primary care, mortality rates are lower.

\section{Patients: difficulties accessing care}

In a recent study, half of adults reported problems obtaining access to care and nearly two-thirds experienced problems with the coordination of their care by providers. ${ }^{44}$ Compared with adults in several other countries, U.S. patients often have extended waits for primary care, with one of five adults reporting a delay of 6 days or more to see a doctor or nurse. Adults also have greater difficulty getting primary care after normal office hours without having to go to a hospital emergency room. Lacking ready access to care, one of five chronically ill adults visited the emergency room for care they could have received from their primary care practice.

\section{Physicians: a difficult practice environment}

Primary care physicians also report many challenges. Compared with their counterparts in other countries, U.S. physicians are far more likely to report that patients cannot afford their treatment and are far less likely to report having electronic patient records and patient registries, e-alert systems regarding patient medications, or other office system supports that enable safe, patient-centered care. In addition, nearly half of primary care physicians work in offices with only one or two practitioners. Because the vast majority of such small practices are not connected to other ambulatory care providers or to hospitals through information systems, coordinating care is extremely difficult. The ACA includes multiple provisions to enhance primary care as listed in Figure $8.45,46$

The ACA adds a new Medicare benefit that will make preventive services more accessible for seniors with diabetes. Beginning in 2011, Medicare will invest $\$ 3.6$ billion to cover a free annual wellness visit during which each beneficiary will receive a personalized prevention plan. The checkup will 


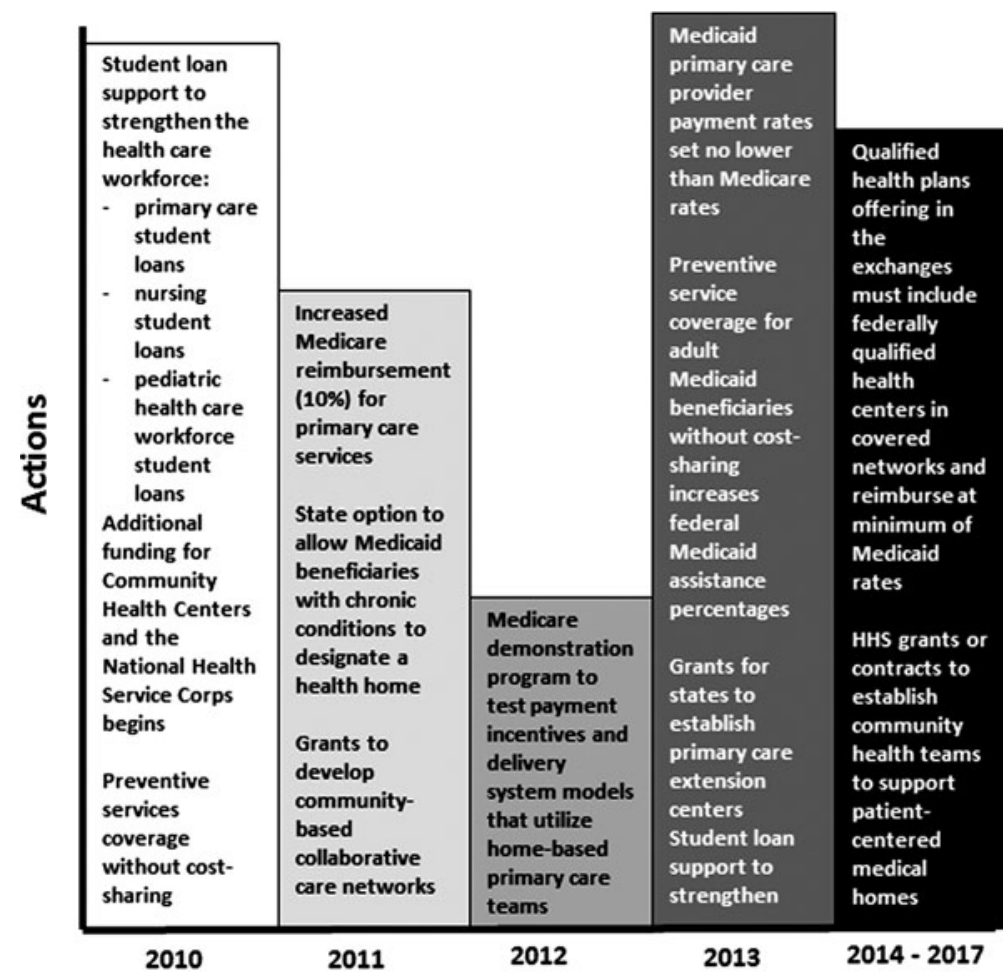

FIG. 8. Scheduled changes in primary care by the Affordable Care Act. HHS, U.S. Department of Health and Human Services. Adapted from Abrams et al. ${ }^{44}$ include a personalized health risk assessment, a review of personal and family medical history, and screening for cognitive impairment. In addition, a list will be compiled of all doctors providing care to the patient. Based on the outcome of the health risk assessment, the patient will receive a 5 to 10 year plan for screenings and other preventive services, as well as advice and referrals for educational services covering weight loss, physical activity, smoking cessation, nutrition, and fall prevention. ${ }^{47}$

\section{Lack of clarity over coverage of secondary prevention}

Although primary prevention services are provided without cost to individuals under the ACA, the provision of secondary prevention costs are not stipulated. Secondary pre- ventive services are designed to identify diseases early so that they can be treated before major disability occurs. Many common diabetes treatments fall under the category of secondary prevention, from statin drugs to prevent cardiovascular disease to annual eye exams to identify diabetic retinopathy at a treatable stage. Because the relationships between costs and benefits with regard to secondary prevention are not always clear, the coverage of secondary prevention can be controversial. The net benefit of a preventive service is determined by evaluating the prevalence and severity of a disease being identified or prevented, the cost and efficacy of the intervention, and the risks associated with treating individuals falsely diagnosed with the condition or who would not otherwise receive treatment. ${ }^{48}$ The ACA did not alter existing coverage and cost-sharing arrangements for certain specific services,

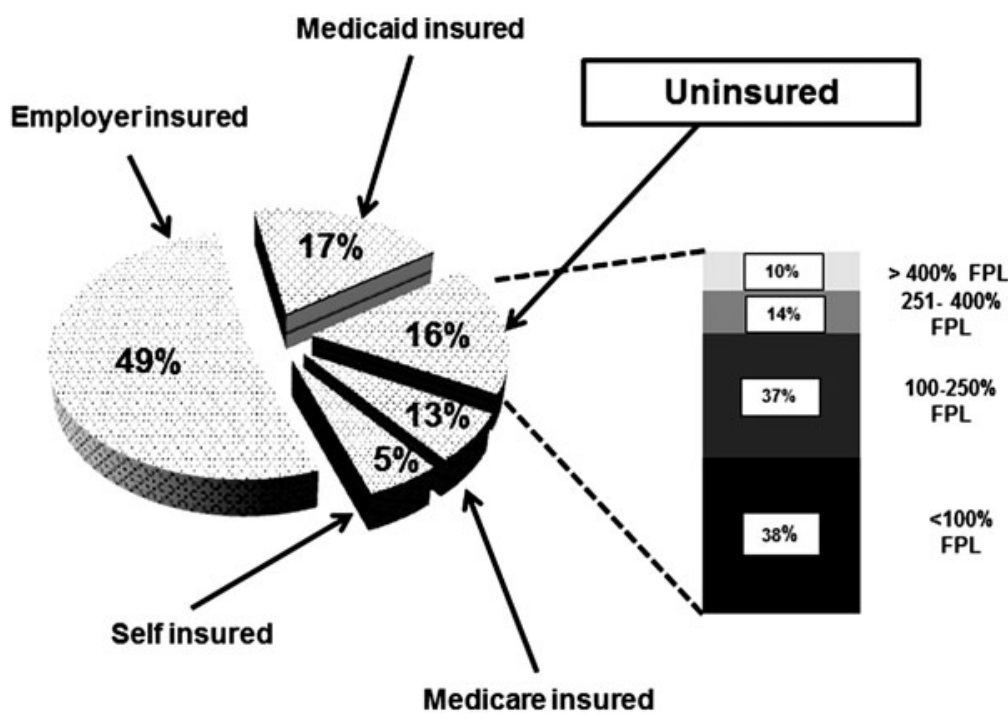

FIG. 9. The uninsured population $(16 \%)$ as a percentage of the total U.S. population is shown in the pie graph. The percentages of the uninsured population in relation the Federal poverty level (FPL) are shown in the bar graph. Adapted from the Congressional Budget Office. ${ }^{19}$ 
such as diabetes self-management training services, which are still subject to deductible and cost-sharing requirements. ${ }^{48}$ Coverage for other secondary prevention diagnostic procedures and interventions that are relevant to the care of diabetes are not stipulated in the ACA legislation, raising the possibility that these costs will be passed along to individuals, thereby adding to the financial burden associated with the ACA for people with diabetes.

\section{Items for Future Enactment}

Even if one assumes that many states that are currently rejecting the expansion of Medicaid will eventually find the opportunity to care for their uninsured populations irresistible, there will still remain many people who remain inadequately covered by the ACA. One analyst estimates that as many as 31 million individuals will be left without healthcare coverage even if the ACA achieves its goals of enlisting 25 million previously uninsured people. ${ }^{49}$ Certain ethnic groups that are disproportionately afflicted with diabetes, such as Hispanics, have not adopted the ACA as avidly as was hoped, leaving a large proportion of the uninsured population apparently bereft of healthcare. In California, where Hispanics make up $46 \%$ of those eligible for subsidized health insurance, only $28 \%$ of health exchange registrants were of Hispanic ethnicity by the close of open enrollment on March 31, $2014 .^{50,51}$ As such, the first priority for the ACA going forward is to meaningfully engage those who have been disenfranchised by the rollout of this large federal program. More important is that the ACA must find a way to protect and increase financial supports for the most financially vulnerable citizens who find the ACA, as it is currently constructed, to be too large a financial burden. This will likely mean shifting the financially vulnerable away from high-deductible, high costshare insurance plans. ${ }^{52}$ Figure 7 shows the national ethnic and minority distribution of new enrollees for healthcare from the federal marketplace.

Aside from these large policy reforms that will improve implementation of the ACA, the provision of dental coverage is a high priority for future enactment under universal healthcare. Adult dental care is not currently covered by the ACA, and the addition of this coverage could represent a significant advance for people with diabetes. ${ }^{53}$ For example, one review demonstrated a threefold increase in risk for severe periodontitis among patients with diabetes,${ }^{54}$ and another study documented 54,000 emergency room visits in Seattle, WA, for dental-related issues over an 18-month period, accounting for $\$ 36$ million in costs. ${ }^{55}$

\section{Summary}

As detailed above, the ACA is major new legislation that will affect every U.S. citizen. Figure 9 provides the percentages of individuals who are insured by various mechanisms versus the percentage of uninsured. Of note is that the uninsured represent all levels of income in the U.S. population. Our description of important parts of the ACA should be of particular interest to caregivers for diabetes patients and should be considered short summaries, not complete descriptions. There is no question that the delivery of healthcare in the United States will change dramatically within the next few years. It is important that healthcare providers understand the main provisions of this new law and advise their patients accordingly. Undoubtedly, there will be amendments and additions to this law so that healthcare givers need to keep abreast of the latest developments. There are many venues that can provide this information, but we would recommend that the ACA Web site (www.healthcare.gov) should always be the first place to start. As caregivers, we can provide a major service to our patients by encouraging them to visit this portal and obtain optimal health coverage for themselves and their families.

\section{Author Disclosure Statement}

No competing financial interests exist.

\section{References}

1. Wikipedia: Patient Protection and Affordable Care Act. May 23, 2014. http://en.wikipedia.org/wiki/Patient_Protection_ and_Affordable_Care_Act (accessed June 2, 2014).

2. Rosen J: Don't Rule Out the New Obama Care Court Challenges. New Republic. www.newrepublic.com/article/ 115850/obamacare-court-challenges-cant-rule-any-them-out (accessed June 2, 2014).

3. Kocher R, Emanuel EJ, DeParle N-A: The Affordable Care Act and the future of clinical medicine: The opportunities and challenges. Ann Intern Med 2010;153:536-539.

4. Kahn R, Anderson JE: Improving diabetes care: the model for health care reform. Diabetes Care 2009;32:1115-1118.

5. Mason K: Federal Health Reform Provisions Related to Diabetes. National Conference of State Legislatures, Denver, Colorado and Washington, DC. www.ncsl.org/portals/ 1/documents/health/DiabetesinHR511.pdf (accessed June 2, 2014).

6. American Diabetes Association: Health Care Reform and People With and At-Risk for diabetes. 2011. http://main .diabetes.org/site/DocServer/HCR_People_with_Diabetes .pdf?docID = 49641 (accessed June 2, 2014).

7. Waters J: Obamacare Aims to Close Medicare 'DoughnutHole.' Wall Street Journal October 6, 2013. http://online.wsj .com/news/articles/SB10001424052702303722604579111170 290397770 (accessed June 10, 2014).

8. Avik R: The Medicare Drug 'Donut Hole' is a Much Smaller Problem Than You Think. Forbes May 25, 2012. http://www.forbes.com/sites/theapothecary/2012/05/25/themedicare-drug-donut-hole-is-a-much-smaller-problem-thanyou-think/ (accessed June 10, 2014).

9. Zhang Y, Donohue JM, Newhouse JP, Lave JR: The effects of the coverage gap on drug spending: A closer look at Medicare Part D. Health Aff (Millwood) 2009;28:w317-w325.

10. Williams JP: How to Make the Best of the Medicare 'Donut Hole.' US News \& World Report October 1, 2013. http:// health.usnews.com/health-news/medicare/articles/2013/10/01/ medicare-donut-hole-how-to-make-the-best-of-it (accessed June 10, 2014).

11. Centers for Medicare \& Medicaid Services: The Affordable Care Act-A Stronger Medicare Program in 2012. February 2013. http://www.cms.gov/apps/files/Medicarereport2012.pdf (accessed June 10, 2014).

12. Nguyen NX: Estimated Savings of $\$ 5,000$ to Each Medicare Beneficiary from Enactment Through 2022 Under the Affordable Care Act. Office of the Assistant Secretary for Planning and Evaluation, Department of Health and Human Services. September 17, 2012. http://aspe.hhs.gov (accessed June 2, 2014).

13. Joyce GF, Zissimopoulos J, Goldman DP: Digesting the doughnut hole. J Health Econom 2013;32:1345-1355. 
14. U.S. Department of Health and Humans Services: At Risk: PreExisting Conditions Could Affect 1 in 2 Americans: 129 Million People Could Be Denied Affordable Coverage Without Health Reform. November 2011. http://aspe.hhs.gov/health/ reports/2012/pre-existing/index.shtml (accessed June 2, 2014).

15. Robertson L: Millions with Pre-existing Conditions. FactCheck.org. February 4, 2011. www.factcheck.org/2011/02/ millions-with-preexisting-conditions/ (accessed June 2, 2014).

16. Greenberg J: Obama Says Half of Americans Have a Preexisting Condition. Politifact.com. September 26, 2013. www.politifact.com/truth-o-meter/statements/2013/sep/27/ barack-obama/obama-says-half-americans-have-preexistingconditi/ (accessed June 2, 2014).

17. Sanz-De-Galdeano: Job-lock and public policy: Clinton's second mandate. Indust Labor Relations Rev 2006;59:430-437.

18. Rogowski J, Karoly L: Health insurance and retirement behavior: evidence from the health and retirement survey. J Health Econom 2000;19:529-539.

19. Congressional Budget Office, Congress of the United States: Updated Estimates of the Effects of the Insurance Coverage Provisions of the Affordable Care Act, April 2014. www.cbo .gov/publication/45231 (accessed June 2, 2014).

20. Fletcher JM, Richards MR: Diabetes's 'health shock' to schooling and earnings: increased dropout rates and lower wages and employment in young adults. Health Aff (Millwood) 2012;31:27-34.

21. HealthCare.gov. What If I Have a Grandfathered Health Insurance Plan? https://www.healthcare.gov/what-if-ihave-a-grandfathered-health-plan/ (accessed June 2, 2014).

22. ObamaCare Facts: Obama Care: Women's Health Services. http://obamacarefacts.com/obamacare-womens-health-services .php (accessed June 2, 2014).

23. Centers for Disease Control and Prevention: Diabetes Report Card 2012: National and State Profile of Diabetes and Its Complications. Atlanta: U.S. Department of Health and Human Services, 2012. www.cdc.gov/diabetes/pubs/ reportcard.htm (accessed June 2, 2014).

24. NovoNordisk: Preventing Type 2 Diabetes. Changing Diabetes Barometer. 2013. www.changingdiabetesbarometer .com/us-initiative/current-public-policy/preventing-type2-diabetes.aspx (accessed June 2, 2014).

25. Trust for America's Health: Patient Protection and Affordable Care Act (HR 3590): Selected Prevention, Public Health \& Workforce Provisions. 2012. http://healthyamericans.org/assets/files/Summary.pdf (accessed June 2, 2014).

26. Ratner RE: Diabetes management in the age of national health reform. Diabetes Care 2011;34:1054-1057.

27. Hull J: Bronze May Be the Most Precious Metal under Obamacare. Hull Financial Planning. September 2013. www.hullfinancialplanning.com/bronze-may-be-the-mostprecious-metal-under-obamacare/ (accessed June 2, 2014).

28. Obamacare Facts: Obamacare Facts: Types of Health Insurance Plans. The Types of Health Insurance Plans Sold On and Off of ObamaCare's Marketplace. http://obamacarefacts .com/insurance-exchange/health-insurance-plans.php (accessed June 2, 2014).

29. Kaiser Family Foundation: A Guide to the Supreme Court's Decision on the ACA's Medicaid Expansion. 2012. http://kff .org/health-reform/issue-brief/a-guide-to-the-supreme-courtsdecision/ (accessed June 2, 2014).

30. Taylor A: Affordable Care Act will cost less than expected, CBO reports. PBS Newshour 2014. http://www.pbs.org/ newshour/rundown/cbo-lowers-projections-cost-health-carelaw/ (accessed June 10, 2014).
31. Aravosis J: Original 1989 document where Heritage Foundation created Obamacare's individual mandate. AmericaBlog October 24, 2013. http://americablog.com/2013/10/original1989-document-heritage-foundation-created-obamacaresindividual-mandate.html (accessed June 10, 2014).

32. Dickman S, Himmelstein D, McCormick D, Woolhandler S: Opting Out Of Medicaid Expansion: The Health And Financial Impacts. Health Affairs Blog. January 2014. http:// healthaffairs.org/blog/2014/01/30/opting-out-of-medicaidexpansion-the-health-and-financial-impacts/ (accessed June 2, 2014).

33. Oberlander J, Perreira K: Implementing Obamacare in a red state-dispatch from North Carolina. N Engl J Med 2013; 369:2469-2471.

34. Miller JE, Lentz C, Maududi N, Harding J: The Waterfall Effect: Transformative Impacts of Medicaid Expansion on States. National Association of State Mental Health Program Directors. January 2013. www.nasmhpd.org/docs/ publications/NASMHPDMedicaidExpansionReportFinal .pdf (accessed June 2, 2014).

35. Franks P, Clancy CM, Gold MR: Health insurance and mortality: evidence from a national cohort. JAMA 1993; 270:737-741.

36. Sommers BD, Baicker K, Epstein AM: Mortality and access to care among adults after state Medicaid expansions. N Engl J Med 2012;367:1025-1034.

37. Finkelstein A, Taubman S, Wright B, Bernstein M, Gruber J, Newhouse JP, Allen H, Baicker K; Oregon Health Study Group: The Oregon health insurance experiment: evidence from the first year. Q J Econ 2012;127:1057-1106.

38. Baicker K, Taubman SL, Allen HL, Bernstein M, Gruber JH, Newhouse JP, Schneider EC, Wright BJ, Zaslavsky AM, Finkelstein AN; Oregon Health Study Group, Carlson M, Edlund T, Gallia C, Smith J: The Oregon experiment: effects of Medicaid on clinical outcomes. N Engl J Med 2013;368:1713-1722.

39. Sommers BD: Improving health through coverage expansion. Ann Intern Med 2014;160:649-650.

40. American Diabetes Association: The Cost of Diabetes. October 21, 2013, http://www.diabetes.org/advocacy/newsevents/cost-of-diabetes.html (accessed June 2, 2014).

41. Stockwell MA: The Cost of Diabetes. DiabetesHealth. October 9, 2010. http://diabeteshealth.com/read/2010/10/ 09/6898/the-cost-of-diabetes/ (accessed June 2, 2014).

42. Steber M: Tax Law Changes in 2013 from the Affordable Care Act (ACA) That Affect Higher Income Earners. Huffingtonpost. 2013. www.huffingtonpost.com/mark-steber/ tax-law-changes-in-2013-f_b_3873024.html (accessed June 2, 2014).

43. Nitti T: Obamacare Investment Income: A Downloadable Cheat Sheet. Forbes December 5, 2012. www.forbes.com/ sites/anthonynitti/2012/12/06/cheat-sheets-to-the-obamacareinvestment-income-tax-regulations-a-downloadable-pdf/ (accessed June 2, 2014).

44. Abrams M, Nuzum R, Mika S, Lawlor G: Realizing Health Reform's Potential: How the Affordable Care Act Will Strengthen Primary Care and Benefit Patients, Providers, and Payers. The Commonwealth Fund. www.commonwealthfund .org/ /media/Files/Publications/Issue\%20Brief/2011/Jan/ 1466_Abrams_how_ACA_will_strengthen_primary_care_ reform_brief_v3.pdf (accessed June 2, 2014).

45. Bodenheimer T, Pham HH: Primary care: current problems and proposed solutions. Health Aff (Millwood) 2010;29: 799-805. 
46. Bodenheimer $\mathrm{T}$, Berenson RA, Rudolf $\mathrm{P}$ : The primary care-specialty income gap: why it matters. Ann Intern Med 2007;146:301-306.

47. Kritz F: 9 Freebies You'll Soon Be Getting Under Obamacare. Takepart. May 13, 2013. www.takepart.com/article/ 2013/05/13/obamacare-healthcare-freebies (accessed June 2, 2014).

48. Cassidy A: Preventive Services Without Cost Sharing. HealthAffairs. Health Policy Briefs. December 28, 2010. www.healthaffairs.org/healthpolicybriefs/brief.php?brief_ $\mathrm{id}=37$ (accessed June 2, 2014).

49. Kliff S, Sun LH: Left Behind: Stories from Obamacare's 31 Million Uninsured. Wonkblog. The Washington Post September 8, 2013, www.washingtonpost.com/blogs/wonkblog/ wp/2013/09/08/left-behind-stories-from-obamacares-31-millionuninsured/ (accessed June 2, 2014).

50. Newsmax.com: Latinos Being Left Behind by Obamacare. March 30, 2014. www.newsmax.com/Newsfront/obamcareHispanics-left-behind/2014/03/25/id/561563/ (accessed June 2, 2014).

51. Millman J: Facing Obamacare Deadline, More Young People Signed Up in March. Washington Post April 4, 2014. www.washingtonpost.com/blogs/wonkblog/wp/2014/04/04/ facing-obamacare-deadline-more-young-people-signed-upin-march/ (accessed June 2, 2014).

52. Wharam JF, Ross-Degnan D, Rosenthal MB: The ACA and high-deductible insurance-strategies for sharpening a blunt instrument. N Engl J Med 2013;369:1481-1484.

53. Free Library: New Findings Show Treating Gum Disease Can Lower Pharmacy Costs for People with Diabetes. 2012. www.thefreelibrary.com $/ \% 20 \mathrm{New}+$ findings + show + treating + gum + disease + can + lower + pharmacy + costs + for...-a0308396236 (accessed June 2, 2014).

54. Preshaw PM, Alba AL, Herrera D, Jepsen S, Konstantinidis A, Makrilakis K, Taylor R: Periodontitis and diabetes: a two-way relationship. Diabetologia 2012;55:21-31.

55. Inge R: Expand Affordable Care Act to Cover Adult Dental Care. Seattle Times September 22, 2013. http://seattletimes .com/html/opinion/2021864371_roningeopeddentalcareobamacare23xml.html (accessed June 2, 2014).

56. HealthCare.gov: What Are My Preventative Care Benefits? https://www.healthcare.gov/what-are-my-preventive-carebenefits/ (accessed June 2, 2014).

57. Adleman A: ACA Bronze Tier Health Insurance vs. Catastrophic Plans: Comparing the coverage of the Affordable
Care Act's Bronze and Catastrophic health insurance plans. US News and World Report. August 13, 2013. http://health .usnews.com/health-news/health-insurance/articles/2013/08/ 28/aca-obamacare-bronze-tier-vs-catastrophic-health-insurance (accessed June 2, 2014).

58. ObamaCare Facts: ObamaCare's Individual Mandate: What is the Tax Penalty for Not Having Health Insurance? http:// obamacarefacts.com/obamacare-individual-mandate.php (accessed June 2, 2014).

59. Congressional Budget Office: Effects of the Affordable Care Act on Health Insurance Coverage-Baseline Projections. February 4, 2014. http://cbo.gov/sites/default/files/ cbofiles/attachments/43900-2014-04-ACAtables2.pdf (accessed June 2, 2014).

60. The Advisory Board Company: Advisory Board Company Daily Briefing: Where the States Stand on Medicaid Expansion. March 2014. www.advisory.com/daily-briefing/ resources/primers/\%20medicaidmap\#lightbox/1/ (accessed June 2, 2014).

61. Kaiser Family Foundation: Where Are States Today? Medicaid and CHIP Eligibility Levels for Children and Non-Disabled Adults as of January 1, 2014. http://kff.org/ medicaid/fact-sheet/where-are-states-today-medicaid-andchip/ (accessed June 2, 2014).

62. Society for Cardiovascular Angiography and Interventions: Medicare and the Affordable Care Act. SecondsCount. www.scai.org/SecondsCount/Resources/Detail.aspx?cid $=$ 7b2a878e-693e-4c89-8088-bf377696df3c\#.U4zn_ThOW70 (accessed June 2, 2014).

63. Assistant Secretary for Planning and Evaluation: 2014 Poverty Guidelines. U.S. Department of Health and Human Services. http://aspe.hhs.gov/poverty/14poverty.cfm (accessed June 2, 2014).

64. ObamaCare Facts. ObamaCare Essential Health Benefits. http://obamacarefacts.com/essential-health-benefits.php (accessed June 2, 2014).

Address correspondence to:

Mark R. Burge, MD

University of New Mexico School of Medicine UNM SOM INT MED MSC10_5550

1 University of New Mexico Albuquerque, NM 87131-0001

E-mail:mburge@salud.unm.edu 